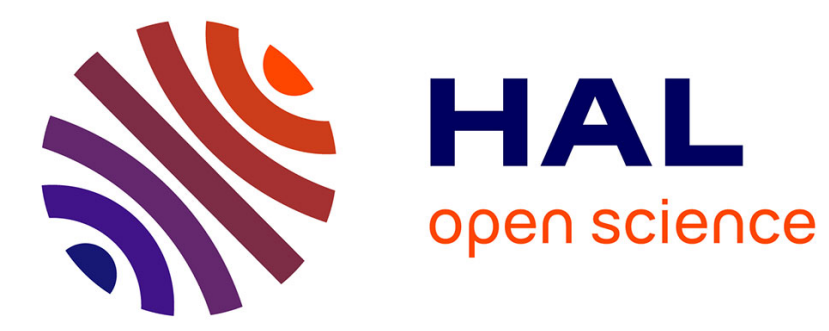

\title{
Improved Class-K amplifier for headset applications
}

E Sturtzer, Gaël Pillonnet, A Huffenus, N Abouchi, F Goutti, V Rabary

\section{To cite this version:}

E Sturtzer, Gaël Pillonnet, A Huffenus, N Abouchi, F Goutti, et al.. Improved Class-K amplifier for headset applications. IEEE International NEWCAS Conference, 2010, Montreal, Canada. pp.5, 10.1109/NEWCAS.2010.5603759 . hal-01103672

\section{HAL Id: hal-01103672 \\ https://hal.science/hal-01103672}

Submitted on 15 Jan 2015

HAL is a multi-disciplinary open access archive for the deposit and dissemination of scientific research documents, whether they are published or not. The documents may come from teaching and research institutions in France or abroad, or from public or private research centers.
L'archive ouverte pluridisciplinaire HAL, est destinée au dépôt et à la diffusion de documents scientifiques de niveau recherche, publiés ou non, émanant des établissements d'enseignement et de recherche français ou étrangers, des laboratoires publics ou privés. 


\section{Improved Class-K amplifier for headset applications}

\author{
E. Sturtzer, G. Pillonnet, A. Huffenus, N. Abouchi \\ University of Lyon \\ Lyon Institute of Nanotechnology (INL) \\ Lyon, France \\ eric.sturtzer@cpe.fr,inl@cpe.fr
}

\author{
F. Goutti, V. Rabary \\ STMicroelectronics \\ Standard Linear Division \\ Grenoble, France \\ frederic.goutti@st.com
}

\begin{abstract}
This paper proposes an improved Class-K audio amplifier as an alternative solution to Class-AB and Class-G audio amplifiers for Headset applications. The Class-K architecture consists in a linear and a switching amplifier connected in parallel to the same speaker. The advantage of this solution is to associate the power efficiency of the switching amplifier with the linearity of a linear amplifier. However, the Class-K may suffer from static consumption. Three methods are presented in order to compensate the topology's disadvantages: a ternary modulation, a two-stage linear amplifier and a low idle switching amplifier. In this paper, we present the Class-K operating principle, a topological comparison and solutions to improve high static consumption. The simulation results prove the validity of these solutions, achieving less than $2 \mathrm{~mA}$ of static current.
\end{abstract}

Keywords-Analog circuits; hybrid audio amplifier; static consumption; low idle switching amplifier; two-stage linear amplifier; ternary modulation.

\section{INTRODUCTION}

During the last few years, there has been a growing market demand for audio amplifiers in multimedia equipment such as computers or mobile phones. Audio amplifiers in those equipments, despite they only have little space available, become smaller and smaller with a high output power and less consumption. Before switching amplifiers [1], linear amplifiers were the only electrical solution to amplify audio signals. They are still used in numerous applications thanks to their very good linearity when they reproduce audio signals. Audio amplifiers are usually classified in three groups: linear amplifiers, switching amplifiers and hybrid amplifiers. Each group contains different structures named: Class-A, B, AB and $\mathrm{C}$ for linear amplifiers, Class-D, $\mathrm{E}$ and $\mathrm{F}$ for switching amplifiers and Class- $\mathrm{G}, \mathrm{H}$ and $\mathrm{K}$ hybrid amplifiers.

Switching amplifiers, especially Class-D amplifiers [2] are currently used for handsfree applications in embedded systems because they have a sufficient linearity (less than $1 \%$ of total harmonic distortion) associated with a high efficiency (90\% at maximum power) [3]. But they are generally not used for high end audio applications, such as headset because the audio quality specification is higher and the static current consumption must be lower than few $\mathrm{mA}$.

The common Class-AB amplifiers are a well established solution, but they suffer from a high thermal dissipation. Class$\mathrm{G}$ is a serial hybrid evolution described in figure 1. Although
Class-G improves the efficiency, our study let us think that Class-K could fit better in this kind of applications.
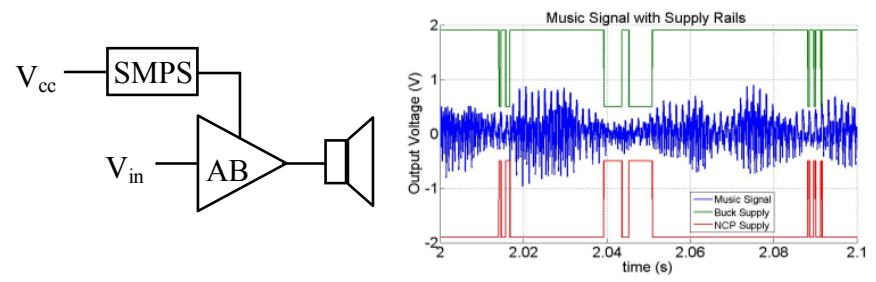

Figure 1. Standard block diagram and signals of a two level Class-G (Class-AB using a Switched-Mode Power Supply).

The objective of this work is the study of such a solution for capless headset (with symmetrical supply). Class-K topology will be introduced: principle, static consumption, power and efficiency analysis are given. Then Class-K will be compared to Class-AB and Class-G. After that, solutions to improve consumption are proposed. Finally, simulation results will be given to prove the validity of these solutions.

\section{CLASS-K AUDIO AMPLIFIER}

The prior work [3] used the hysteresis topology [4] but this architecture is not applicable for headset applications, because a known switching frequency is preferred.

\section{A. Class-K principle}

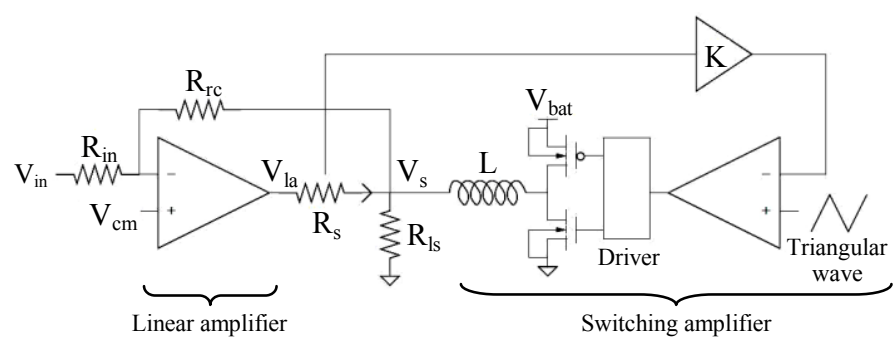

Figure 2. Block diagram of "binary PWM Class-K".

The Class-K using binary PWM architecture (Class-K1 or Class-K1B), proposed by [5], is presented in figure 2. The principle of Class- $\mathrm{K}$ is to use a switching amplifier (SA) controlled by the output current of a linear amplifier (LA). They are both connected in parallel to the load $\left(\mathrm{R}_{\mathrm{ls}}\right)$. The $\mathrm{SA}$ drives the load through an inductance and could be seen as a current source controlled by LA output current. The LA feedback control adjusts the output voltage $V_{\mathrm{s}}$ to the reference audio signal $\mathrm{V}_{\text {in }}$.

The authors would like to thank the standard linear division, particularly audio team from STMicroelectronics (Grenoble, France). 


\section{1) Modeling Class-K PWM}

The Class K1 PWM amplifier design is modeled in Matlab Simulink environment to characterize its behavior (the SimElectronics toolbox has been used). The models used for this system are a result of subsequent simplifications including: infinite LA bandwidth ( $\mathrm{A}_{\mathrm{la}}$ close to infinite, $\tau_{\mathrm{la}}$ equal to zero), double sided linear ramp generation, ideal SA power stage, stable power supply and ground, linear inductor and resistors, purely resistive load and ideal comparator. However, this level of modeling can be used in order understand the behavior of this system. Following simulations use $\mathrm{R}_{\mathrm{rc}}=\mathrm{R}_{\mathrm{in}}=100 \mathrm{k} \Omega, \mathrm{R}_{\mathrm{s}}=1 \Omega$, $\mathrm{R}_{\mathrm{ls}}=32 \Omega, \mathrm{V}_{\text {bat }}=3.6 \mathrm{~V}, \mathrm{~K}=1$ and $\mathrm{V}_{\mathrm{cm}}=1 \mathrm{~V}$.

\section{2) Power delivered by Linear and Switching Amplifier}

The power delivered by LA and SA is one of the most relevant characteristics of a Class $\mathrm{K}$ audio amplifier. The efficiency of this structure is directly dependent of the ratio $\mathrm{i}_{\mathrm{la}} / \mathrm{i}_{\mathrm{sa}}$. In fact, the LA and SA have respectively low and high efficiencies. In steady-state, without considering the high frequency component, the output currents in both amplifiers are expressed in (1).

$$
i_{l a}=\frac{R_{l s}}{K_{i}} i_{s} \quad i_{s a}=\left(1-\frac{R_{l s}}{K_{i}}\right) i_{s}
$$

Where $K_{i}=R_{s} G_{p w m} K=\frac{2 R_{S} K V_{b a t}}{\Delta V}, \Delta \mathrm{V}$ is the amplitude of the ramp, $V_{\text {bat }}$ the power supply voltage. The figure 3 shows the LA, SA and output currents when the input reference a rail to rail pure sine wave at $1 \mathrm{kHz}\left(\mathrm{L}=200 \mu \mathrm{H}, \mathrm{f}_{\mathrm{pwm}}=100 \mathrm{MHz}\right.$, $\Delta \mathrm{V}=40 \mathrm{mV})$. In this case, the ratio between LA and load current is $18 \%$. The SA provides $82 \%$ of the output current, providing a high efficiency to the Class-K architecture.

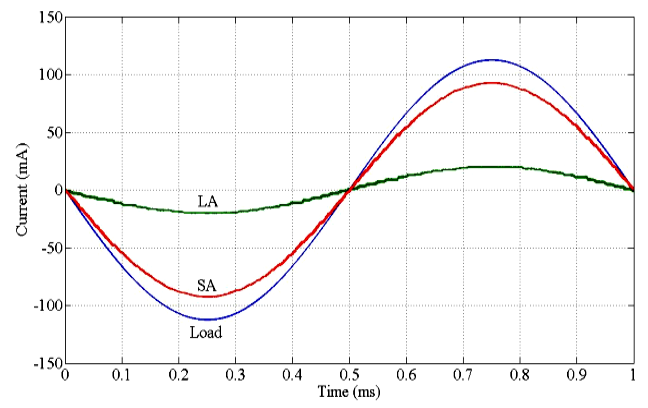

Figure 3. LA, SA and load currents with input signal.

\section{3) Static consumption}

The high gain of the LA feedback compensates the output voltage oscillation introduced by the PWM modulation. The LA current compensates the inductor current ripple all the time [6]. The LA has the same function as an active filter to compensate the PWM high-frequency components. This interaction causes a static consumption depends on the lowpass filter time constant (L/R) and the PWM frequency. The LA and SA static currents can be expressed as in (2).

$$
I_{0_{r m s}}=\frac{V_{\text {bat }}}{2 \sqrt{3} L f_{p w m}}
$$

With $\mathrm{V}_{\text {bat }}=3.6 \mathrm{~V}, \mathrm{f}_{\mathrm{pwm}}=10 \mathrm{MHz}$ and $\mathrm{L}=20 \mu \mathrm{H}$, the static current is $\mathrm{I}_{0}=5.2 \mathrm{~mA}$, equivalent to the $4.8 \mathrm{~mA}$ static current of a
Class-AB [7] but a large value compared to the $1.2 \mathrm{~mA}$ static current of a Class-G [8]. This confirm that Class-K suffer from high static consumption compare to other topologies. Solutions to improve this problem will be given in section III.

\section{4) Power efficiency analysis}

\section{a) SA power looses}

The SA power consumption given in (3) is composed of the power to the load $\mathrm{P}_{\mathrm{u}}$ conduction losses $\mathrm{P}_{\text {cond, }}$, switching looses $\mathrm{P}_{\mathrm{sw}}$, and quiescent power $\mathrm{P}_{\mathrm{q}}[9]$.

$$
P_{d}=\underbrace{V_{s r m s} I_{s a_{r m s}}}_{P_{u}}+\underbrace{R_{\text {on }}\left(I_{\text {sa }}^{2}+\bar{I}_{0}^{2}\right)}_{P_{\text {cond }}}+\underbrace{2 C_{p} V_{b a t}^{2} f_{p w m}}_{P_{s w}}+\underbrace{2 V_{c c} I_{q_{s a}}}_{P_{q}}
$$

With $\mathrm{R}_{\mathrm{on}}$ the resistor value of SA's power transistors, $\mathrm{C}_{\mathrm{p}}$ the transistor gate capacitance, $\mathrm{I}_{\mathrm{qsa}}$ the quiescent current of PWM modulator and current sensing block, $I_{0}$ the RMS static consumption. The RMS SA current, RMS output voltage and average of static current can respectively be expressed as:

$I_{s a_{r m s}}=\frac{M V_{b a t}}{R \sqrt{2}}\left(1-\frac{R_{l s}}{K_{i}}\right) \quad V_{s_{r m s}}=\frac{M V_{b a t}}{\sqrt{2}} \quad \overline{I_{0}}=\frac{V_{\text {bat }}}{4 L f_{p w m}}$

\section{b) LA power looses}

The LA power consumption is composed of the dissipate power in the power stage $\left(\mathrm{V}_{\mathrm{ds}} \mathrm{I}_{\mathrm{ds}}\right)$ and quiescent power (bias current and oscillation current losses explained in the previous subsection) as shown in (5).

$$
P_{l a}=\frac{1}{\eta_{l a}} P_{u}+2 V_{b a t} I_{q_{l a}}+\frac{V_{b a t}^{2}}{4 L f_{p w m}}\left(1-\frac{M}{\sqrt{2}}\right) e^{\frac{2 M L f_{p w m}}{K_{i}}}
$$

Where $\eta_{\text {la }}$ is the efficiency of the LA amplifier, $I_{\mathrm{qla}}$ the LA quiescent current, and $\mathrm{P}_{\mathrm{u}}$ the power provided to the load. The efficiency and the load power can be expressed as:

$$
\eta_{l a}=\frac{\pi}{4} M \quad P_{u}=\frac{M^{2} v_{b a t}^{2}}{2 K_{i}}
$$

c) Class-K PWM efficiency

The efficiency [10] of Class-K PWM is:

$$
\eta_{k}=\frac{P_{s}}{P_{l a}+P_{s a}} \quad P_{S}=\frac{M^{2} v_{b a t}^{2}}{2 R_{l s}}
$$

Figure 4 illustrates the efficiency of Class-K PWM, our proposed efficiency model and a Classical Class-AB amplifier solution when the output power varies (conditions: $\mathrm{C}_{\mathrm{p}}=100 \mathrm{pF}$, $\left.\mathrm{R}_{\mathrm{on}}=4 \Omega, \mathrm{f}_{\mathrm{in}}=1 \mathrm{kHz}, \mathrm{L}=200 \mu \mathrm{H}, \mathrm{f}_{\mathrm{pwm}}=1 \mathrm{MHz}, \mathrm{R} / \mathrm{K}_{\mathrm{i}}=0.18\right)$.

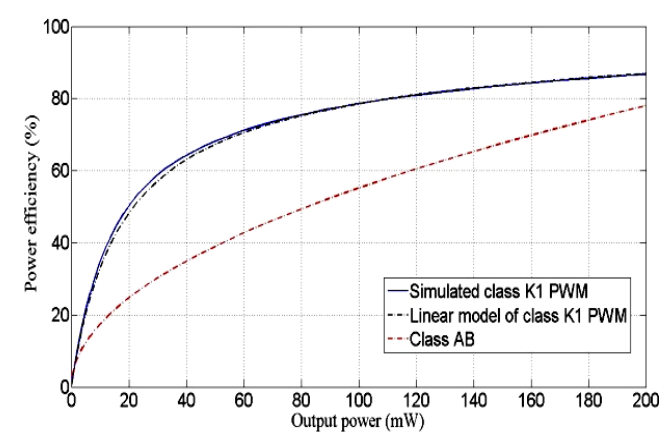

Figure 4. Class-K PWM efficiency versus output power. 


\section{B. Topological comparison}

Table I presents a quick comparison between the different audio amplifier topologies. Class-AB has the best quality reproduction but it has a reduced efficiency. Class-D is efficient but has a low reproduction quality and the Class-G and $\mathrm{K}$ are good tradeoffs between audio quality and efficiency.

TABLE I. COMPARISON BETWEEN DIFFERENT AUDIO AMPLIFIERS

\begin{tabular}{|c|c|c|c|c|}
\hline Class & $\begin{array}{c}\text { Reproduction } \\
\text { quality }\end{array}$ & $\begin{array}{c}\text { Efficiency } \\
\text { (full scale) }\end{array}$ & $\begin{array}{c}\text { Efficiency } \\
\text { (middle power) }\end{array}$ & $\begin{array}{c}\text { Efficiency } \\
\text { (low power) }\end{array}$ \\
\hline AB & ++ & -- & -- & -- \\
\hline D & - & ++ & ++ & - \\
\hline G & + & + & + & + \\
\hline K & + & + & + & + \\
\hline
\end{tabular}

\section{1) Comparison with Class- $A B$}

The figure below shows the consumption current ratio between Class-AB and Class-K1 PWM. The main advantage of the Class-K structure is the power efficiency at medium and high output power (superior to $1 \mathrm{~mW}$ in the above example). The static current is the main drawback to develop this system for integrated and low static consumption audio amplifiers, such as in mobile phones.

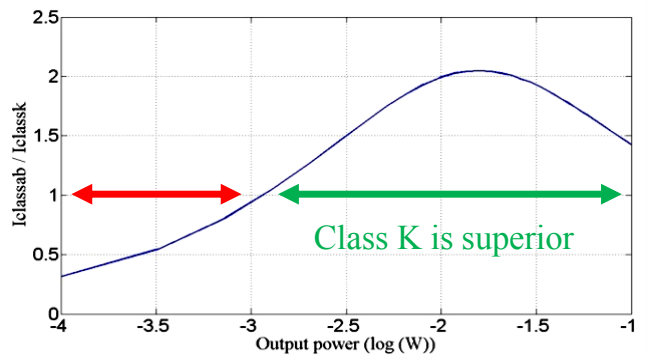

Figure 5. Class-K PWM vs Class AB consumption ratio.

\section{2) Comparison with Class-G}

The main advantage is that most of the power is provided by the efficient SA and that the LA controls the output voltage to correct non linearities. Another advantage is the equivalent resistance of the amplifiers which could be smaller (compared to Class-G) because of parallel connection. The main drawback of Class-K PWM is idle consumption due to the LA's compensation of the SA's output ripple current. The second drawback is that the LA's idle power consumption could be higher than LA of Class-G, even if the LA provides less current, because this LA is powered between $-V_{\text {bat }}$ and $V_{\text {bat }}$ instead of a portion of $\mathrm{V}_{\text {bat }}$ in Class-G. The last drawback: the SA is always modulating in opposition to Class- $\mathrm{G}$ which could use a Pulse-frequency mode (PFM) for its SMPS. Three solutions can be used to limit these drawbacks: ternary modulation, two stages LA and SA power stage with low idle consumption.

\section{SOLUTIONS TO IMPROVE STATIC CONSUMPTION}

\section{A. Ternary modulation}

The limitation for binary PWM (Class-K1B) is the static consumption introduced by the coupling between LA and SA. The proposed solution is the use of a ternary PWM modulation
(Class-K1T) to reduce static current consumption. If a three level SA is used, the SA's output voltage can be set to zero when there is no input, instead of switching between low and high supply voltage. In this case, the LA amplifier has not to compensate the ripple, because there is almost none.

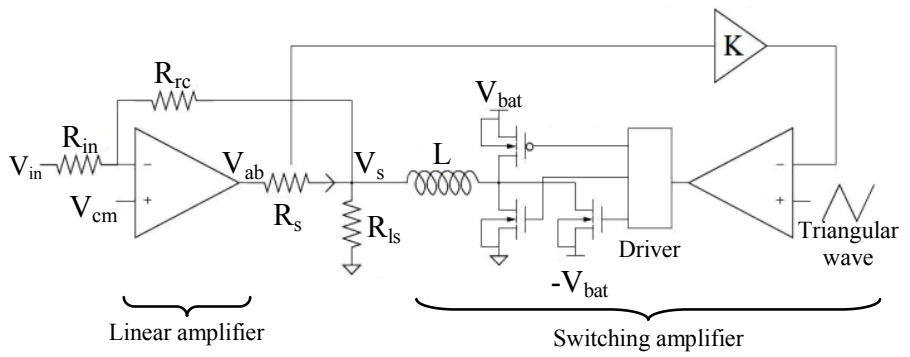

Figure 6. Block diagram of Class-K1T.

Figure 7 shows the improvement of the ternary modulation in the Class- $\mathrm{K}$ architecture with $\mathrm{R}_{\mathrm{i}}=0.18 \Omega$ (conditions: $\mathrm{C}_{\mathrm{p}}=100 \mathrm{pF}, \quad \mathrm{R}_{\mathrm{on}}=4 \Omega, \quad \mathrm{f}_{\mathrm{in}}=1 \mathrm{kHz}, \quad \mathrm{L}=200 \mu \mathrm{H}, \quad \mathrm{f}_{\mathrm{pwm}}=1 \mathrm{MHz}$, $\mathrm{I}_{\mathrm{qsa}}=\mathrm{I}_{\mathrm{qla}}=0, \mathrm{~A}_{\mathrm{la}}=80 \mathrm{~dB}, \mathrm{f}_{\mathrm{la}}=100 \mathrm{~Hz}$ ). Now, the Class-K could be a challenger for the targeted applications.

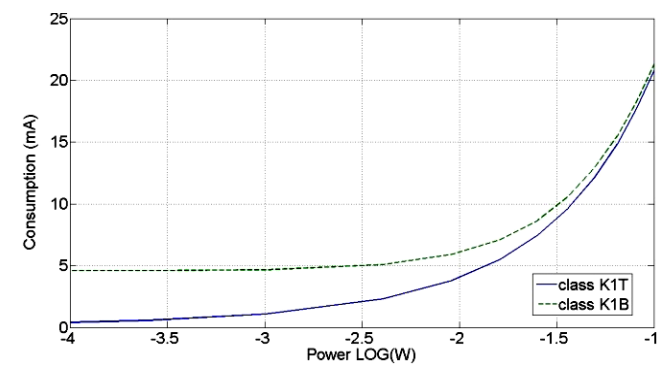

Figure 7. Class-K comsumption (binary and ternary) vs. output power

The figure 8 shows the current consumption ratio between the Class-K1T and Classical linear and Class-G solutions. We consider that the SA's power stage switching losses are reduced by reducing the amplitude of the gate command voltage $\left(\mathrm{P}_{\mathrm{sw}}=0.5 \mathrm{C}_{\mathrm{p}} \mathrm{V}_{\mathrm{cc}}{ }^{2}\right)$. The Class-G has both power supplies $\left(\mathrm{V}_{\mathrm{batG}}, \mathrm{V}_{\mathrm{bat}}\right)$ and the Class-G switching power supply which provides the $\mathrm{V}_{\mathrm{batG}}$ has the same efficiency as Class-K's LA $\left(\mathrm{C}_{\mathrm{g}}=100 \mathrm{pF}, \mathrm{R}_{\mathrm{on}}=4 \Omega\right)$. Efficiencies are given in (8).

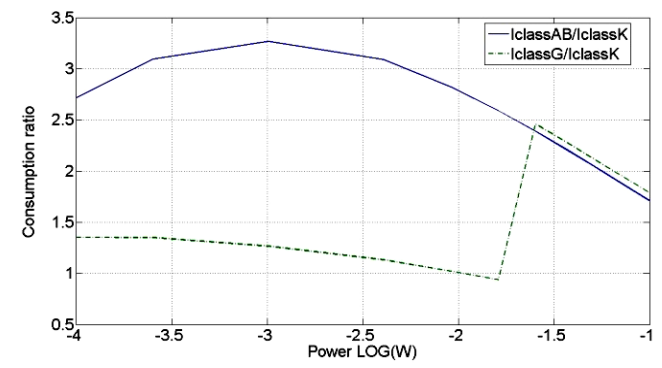

Figure 8. ClassK1T consumption versus others amplifiers solutions.

$$
\begin{aligned}
& \eta_{G}=\eta_{l a} \eta_{\text {smps }} \quad \eta_{l a}=\frac{\pi M V_{\text {bat }}}{4 V_{\text {bat }}} \\
& \eta_{\text {smps }}=\frac{P s_{s m p s}}{P s_{s m p s}+R_{o n} I_{s m p s}^{2}+0.5 C_{p} V_{b a t}^{2}+I_{q} q_{p w m} V_{b a t}} \\
& P S_{s m p s}=\frac{M^{2} V_{b a t}^{2}}{2 R \eta_{l a}} \quad I_{s m p s}=\frac{P s_{s m p s}}{V_{b a t}}
\end{aligned}
$$


The Class-K's consumption is always lower than with the Class-AB solution. For Class- $G$ comparison (at $f_{i n}=10 \mathrm{kHz}$ ), the Class-K efficiency gain depends on the Class-G's supply (here, $1.2 \mathrm{~V}$ ). At $0.9 \mathrm{~V}$, the Class-G is the best solution between $1 \mathrm{~mW}$ and $15 \mathrm{~mW}$, because of the improvement of its LA efficiency $(30 \%$ more than with $1.2 \mathrm{~V})$. The simulation with an audio track (voice music style) at $1 \mathrm{~mW}$ confirms the Class-K's gain. The Class- $\mathrm{AB}, \mathrm{G}$ and $\mathrm{K}$ efficiencies are respectively $4.7 \%, 11.7 \%$ and $14.4 \%$. At $10 \mathrm{~mW}$, the gap increases: 16,27 and $40 \%$. The same results are obtained with a techno music style. To conclude, the Class-K solution reduces the power consumption between 20 and $30 \%$, in function of the output power. The Class-K's efficiency gain depends on the electrical implementation of the SA's power stage and the static current of PWM, current sensing and LA. If we consider the MOS drift performance which composes the Class K SA power stage, its consumption increases (ratio between $R_{\text {on }}$ and $C_{p}$ is lower than a Classical high voltage MOS in Class G's SMPS).

\section{B. Two stages linear amplifier}

Using the LA and SA connected in parallel will reduce the load seen from the LA's side, involving a lower static current of LA for the same gain bandwidth product.
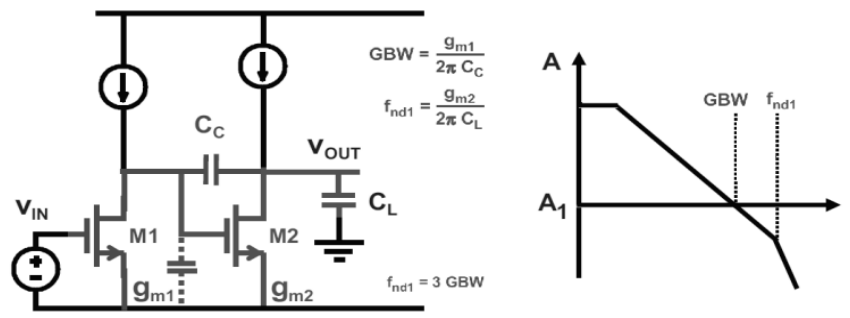

Figure 9. Two-stage Miller CMOS OTA principle with gain response.

For the LA, $1 \mathrm{MHz}$ is a good GBW. In theory [11], a ratio of three for $f_{\text {nd1 }}$ is taken for a phase margin of about $70^{\circ}$. In reality, 1.2 times more is enough because $45^{\circ}$ phase margin is sufficient.

$f_{n d 1}=\frac{g_{m 2}}{2 \pi C_{L}}=1.2 \mathrm{GBW} \quad G B W=\frac{g_{m 1}}{2 \pi C_{c}} \quad g_{m 2}=\frac{I_{d}}{V_{T} N_{0}}$

With $\mathrm{C}_{\mathrm{L}}=\mathrm{C}_{\mathrm{la}}=1 \mathrm{nF}, \mathrm{V}_{\mathrm{T}}=25 \mathrm{mV}$ and $\mathrm{N}_{0}=2 ; \mathrm{g}_{\mathrm{m} 2}=7.6 \mathrm{mS}$ and $\mathrm{I}_{\mathrm{d}} \approx 380 \mu \mathrm{A}$. In the first stage, if $\mathrm{I}_{\mathrm{q}}=15 \mu \mathrm{A}, \mathrm{G}_{\mathrm{m} 1}=0.3 \mathrm{mS}$ and $\mathrm{C}_{\mathrm{c}}=47.7 \mathrm{pF}$. A two-stage Miller CMOS OTA, instead of a three-stage is a possible solution for Class-K compared to the three-stage from the Class-G.

\section{Switching amplifier power stage}

The main idle loses are the gate drive, the ripple current provide from the coil and parasitic capacitances. Those loses can be reduced using zero voltage switching, choosing the optimal power transistors size and using a CMOS technology with double oxide or drain extension.

\section{SiMULATION RESULTS}

Simulations with Cadence using STMicroelectronics $0.25 \mu \mathrm{m}$ technology transistor models show that a two stage linear amplifier in parallel with a switching amplifier using a ternary modulation is a good solution to reduce static consumption. For $16 \Omega$ load, we choose $33 \mu \mathrm{H}$ and $33 \mathrm{nF}$ for the LC filter, and a switching frequency of $3 \mathrm{MHz}$. The static consumption is estimated at $2 \mathrm{~mA}$ for a single channel with a
THD equivalent to Class-G (Vout $=0.7 \mathrm{~V}_{\mathrm{RMS}}, \quad \mathrm{F}=1 \mathrm{KHz}$, $\mathrm{THD}_{\mathrm{MAX}}=-74 \mathrm{~dB}$ ). Figure 10 shows that the ratio between LA and load current is $14 \%$ and the SA provides $86 \%$ of the power output power.

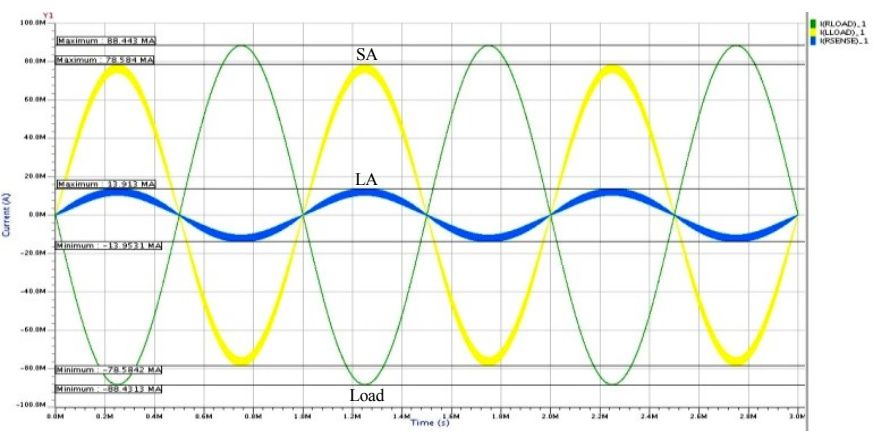

Figure 10. LA, SA and load currents.

\section{CONCLUSION}

This article presents an original topology to increase the efficiency of an audio amplifier driving a headset. It has been shown that it is possible to use linear amplifier coupled with a switching amplifier to reproduce a good audio signal with little extra power dissipation. Different solutions to reduce static current losses of the Class-K topology are proposed. The use of ternary modulation, two-stage LA implementation and low idle SA are discussed. The simulation results show that the Class-K amplifier topology could be an alternative solution to linear amplifier for headset applications.

\section{REFERENCES}

[1] P. J. Baxandall, "Transistor sine-wave LC oscillators," (presented at the Intern. Conv. On Transistors and Associated Semicon. Devices, May 1959), IRE Proc. B, 1959, pp. 748-759.

[2] R. Cellier, G. Pillonnet, A. Nagari, N. Abouchi, "An review of fully digital audio class D amplifiers topologies," NEWCAS-TAISA '09, Toulouse, France, 2009. pp. 1-4.

[3] G. Pillonnet, N. Abouchi, R. Cellier, A. Nagari, “A 0.01\%THD, 70dB PSRR Single Ended Class D using variable hysteresis control for headphone amplifiers," ISCAS, Taipei, Taiwan, 2009, pp. 1181-1184

[4] R. A. R. van der Zee and A. J. M. van Tuijl, "A power efficient audio amplifier combining switching and linear techniques," ESSCIRC, The Hage, The Netherlands, 1998, 288-291.

[5] L. Chiesi, E. Lorenzani, G. Franceschini, and A. Bellini, "Modeling of a parallel hybrid power audio amplifier," Proc. IEEE Ind. Electron. Conf., 2006, pp. 1775-1780.

[6] R. A. R. van der Zee, "High efficiency audio power amplifier," Design and pratical use, $\mathrm{PhD}$ thesis, Univerté Twente, 1999.

[7] R. A. R. van der Zee and A. J. M. van Tuijl, "A power-efficient audio amplifier combining switching and linear techniques," IEEE Journal of Solid-State Circuits, 1999, 34, 985-991.

[8] TS4601B; High performance stereo headphone amplifier with capacitorless output and $\mathrm{I}^{2} \mathrm{C}$ bus interface, Rev. 2, 08-Jul-2008, www.st.com.

[9] TS4621; High performance Class-G stereo headphone amplifier with $\mathrm{I}^{2} \mathrm{C}$ bus interface, Rev. 1, 12-Feb-2010, www.st.com.

[10] K. Nielsen, "Linearity and Effiency Performance of Switching Audio Power Amplifier Output Stages - A fundamental Analysis," $105^{\text {th }}$ AES Convention, San Francisco, 1998.

[11] NS. Jung, NI Kim and GH Cho, "A New High-Efficiency and SuperFidelity Analog Audio Amplifier with the Aid of Digital Switching Amplifier: Class K Amplifier," Proc. 29th IEEE Power Electron. Spec. Conf, 1998, pp. 457-463.

[12] Willy M. C. Sansen, Analog design essensials, Book, Springer, 2008. 
